Research Paper

\title{
Presence of Antibodies against Self Human Leukocyte Antigen Class II Molecules in Autoimmune Hepatitis
}

\author{
Satoshi Yamagiwa ${ }^{\bowtie}$, Hiroteru Kamimura1 ${ }^{1}$, Masaaki Takamura ${ }^{1}$, Takuya Genda², Takafumi Ichida ${ }^{2 *}$, \\ Minoru Nomoto ${ }^{1}$, and Yutaka Aoyagi ${ }^{1}$ \\ 1. Division of Gastroenterology and Hepatology, Niigata University Graduate School of Medical and Dental Sciences, 1-757 Asahimachi-dori, \\ Chuo-ku, Niigata 951-8510, Japan; \\ 2. Department of Gastroenterology and Hepatology, Juntendo University Shizuoka Hospital, 1129 Nagaoka, Izunokuni 410-2295, Japan.
}

* Present address: Department of Gastroenterology and Hepatology, Shonan Tobe General Hospital, 500 Nishikubo, Chigasaki 253-0083, Japan.

$\triangle$ Corresponding author: Satoshi Yamagiwa, M.D., Ph.D. Division of Gastroenterology and Hepatology, Niigata University Graduate School of Medical and Dental Sciences, 1-757 Asahimachi-dori, Chuo-ku, Niigata, 951-8510, Japan. Tel: +81-25-227-2207 Fax: +81-25-227-0776

E-mail address: syamagi@med.niigata-u.ac.jp.

(c) Ivyspring International Publisher. This is an open-access article distributed under the terms of the Creative Commons License (http://creativecommons.org/ licenses/by-nc-nd/3.0/). Reproduction is permitted for personal, noncommercial use, provided that the article is in whole, unmodified, and properly cited.

Received: 2014.0I.21; Accepted: 2014.05.15; Published: 2014.06.08

\begin{abstract}
Autoimmune hepatitis (AlH) can arise de novo after liver transplantation (LT) for non-autoimmune liver diseases. Considering the identical features of de novo AlH after LT and classical AlH, as well as the importance of anti-human leukocyte antigen (HLA) antibodies in graft rejection, we investigated the presence of circulating anti-HLA class II antibodies in the sera of 35 patients with $\mathrm{AlH}$, 30 patients with primary biliary cirrhosis (PBC), and 30 healthy donors using fluorescent dye-impregnated beads bound to HLA molecules. We then investigated the allele specificity of the antibodies and identified the HLA alleles in each patient using DNA-based HLA typing. We also examined HLA class II expression in liver samples using immunohistochemistry. Anti-HLA class II antibodies were detected significantly more frequently in the patients with $\mathrm{AlH}(88.1 \%)$ than in the patients with PBC (33.3\%) or in the healthy donors (13.3\%) (both $P<0.01$ ). We confirmed that the anti-HLA class II antibodies in the AlH patients showed specificity for several HLA class II alleles, including self HLA class II alleles. Moreover, positive reactivity with anti-self HLA class II antibodies was associated with higher serum transaminase levels. In conclusion, we demonstrated, for the first time, that antibodies against self HLA class II alleles were detectable in patients with AlH. Our results suggest that an antibody-mediated immune response against HLA class II molecules on hepatocytes may be involved in the pathogenesis or acceleration of liver injury in $\mathrm{AlH}$.
\end{abstract}

Key words: HLA; AIH; PBC; anti-HLA antibodies.

\section{Introduction}

Autoimmune hepatitis (AIH) is an inflammatory liver disease that is characterized by elevated serum transaminase levels, positive organ-specific and non-specific autoantibodies, elevated serum immunoglobulin (IgG), and histological interface hepatitis in the absence of a known cause of liver disease $[1,2]$. There are two main forms of AIH, which can be distinguished by the presence of different autoantibodies [3]. AIH type 1 is defined by the presence of smooth muscle antibody (SMA), which is mainly observed in polymeric (filamentous, F) actin pattern, and/or by antinuclear antibody (ANA), which is mainly observed in homogeneous pattern. AIH type 2 is defined by liver/kidney microsomal type 1 antibody (anti-LKM1) and/or liver cytosol type 1 antibodies (anti-LC1) [3]. The molecular targets of SMA and ANA have not been characterized, but the main target of anti-LKM1 is the liver cytochrome P4502D6 (CYP2D6), which localizes mainly to the endoplasmic reticulum but also to hepatocyte membranes [4]. Im- 
mune reactions against host liver antigens are believed to be the major pathogenic mechanism of $\mathrm{AIH}$, and the disease responds satisfactorily to immunosuppressive treatment. However, the primary cause of AIH remains unknown [5].

Liver transplantation (LT) is the best treatment option for selected patients with end-stage liver disease caused by AIH [6]. However, despite the good outcomes reported, AIH can recur after LT; AIH and autoimmunity can also arise de novo after LT for non-autoimmune liver diseases [6-8]. The features of de novo AIH after LT are identical to those of classical $\mathrm{AIH}$, such as hypergammaglobulinemia; positive autoantibodies, including ANA, ASMA, and atypical anti-LKM1; and histological findings of interface hepatitis with an abundance of plasma cells [6,9]. Patients who develop de novo AIH do not exhibit a satisfactory response to standard antirejection regimens, but they do respond to the standard treatment for $\mathrm{AIH}$ [6]. However, it remains unclear whether de novo $\mathrm{AIH}$ is a distinct entity or a form of atypical hepatitis in individuals who are at risk of autoimmunity. Moreover, several reports have suggested that de novo AIH may represent an alloimmune response (i.e., a form of rejection), in which immune-mediated injury is directed toward hepatocytes rather than bile ducts or vascular endothelium [10]. Neil et al. also showed overlapping features of histological findings between rejection and de novo $\mathrm{AIH}[10]$.

Allograft rejection was originally believed to be mediated almost exclusively by cellular immune responses, but it has since become clear that humoral responses also play a major role in this process $[11,12]$. Considering the importance of anti-human leukocyte antigen (HLA) antibodies in graft rejection after LT, we focused on their role in AIH because the involvement of antibodies against self HLA molecules on hepatocytes in the liver injury that is characteristic of AIH remains to be elucidated. In the present study, we investigated the presence of anti-HLA class II antibodies in the sera of patients with $\mathrm{AIH}$ and primary biliary cirrhosis (PBC) using a highly sensitive method (Luminex) and evaluated the significance of these antibodies, particularly against self HLA class II molecules whose expression on hepatocytes can be induced by interferon- $\gamma$ (IFN- $\gamma$ ) [13], in the pathogenesis of AIH.

\section{PATIENTS \& METHODS}

\section{Study cohort}

This work was conducted in accordance with the Declaration of Helsinki. After we obtained the appropriate written informed consent under Institutional Review Board-approved protocols (approval no. 413), blood and liver biopsy specimens were collected from 35 female patients with $\mathrm{AIH}$ at disease onset and from 30 female patients with PBC. Blood was also collected from 30 healthy female donors. All the enrolled patients and healthy donors were Japanese. A diagnosis of AIH was made on the basis of the presence of ANA and/or ASMA, according to the classical and simplified criteria defined by the International Autoimmune Hepatitis Group [14,15], and liver biopsy findings compatible with $\mathrm{AIH}$. A diagnosis of $\mathrm{PBC}$ was made on the basis of the presence of antimitochondrial antibody (AMA) and/or AMA-M2 and liver biopsy findings compatible with $\mathrm{PBC}$ $[16,17]$.

\section{Detection of anti-HLA class II antibodies (Luminex assay)}

We investigated the presence of circulating antibodies against HLA class II molecules in the sera using fluorescent dye-impregnated beads bound to HLA molecules (Luminex). Screening anti-HLA tests were performed with multiplex technology (LABScreen mixed test, One Lambda, Canoga Park, CA). When the results were positive, the allele specificity of the antibodies was determined using beads bound to a single HLA class II antigen (LABScreen single-antigen test, One Lambda). Published data indicate that the Luminex platform is the most sensitive of the solid phase antibody detection techniques [18]. HLA antibody specificity was considered positive if the normalized mean fluorescence intensity (MFI) value was greater than 1000 [11].

\section{DNA typing of HLA class II alleles}

In cases that were positive for anti-HLA class II antibodies, we then determined the HLA alleles in each patient using DNA-based HLA typing (PCR-Sequencing-Based Typing) (SRL Inc., Tokyo, Japan).

\section{Immunohistochemistry of HLA class II molecules}

Tissue sections were first deparaffinized with xylene and then rehydrated through graded alcohol. To retrieve antigenicity, sections were immersed in pH 6.0 citrate buffer. After autoclaving, the sections were then immersed in phosphate-buffered saline (PBS) containing $0.3 \%$ hydrogen peroxide for $20 \mathrm{~min}$ to block endogenous peroxidase activity. The sections then were incubated with an anti-HLA class II (HLA-DR, HLA-DP, and HLA-DQ) antibody (clone: CR3/43) (GeneTex, Inc., Irvine, CA) at a 1:25 dilution in PBS supplemented with $3 \%$ BSA at $4^{\circ} \mathrm{C}$ overnight. The sections were followed sequentially using a biotinylated secondary antibody and the avi- 
din-biotin-peroxidase complex method with the Vectastain Elite $\mathrm{ABC}$ kit (Vector Laboratories Inc., Burlingame, CA). The sections were developed with diaminobenzidine (DAB) substrate (Muto Pure Chemicals, Tokyo, Japan). The specimens then were counterstained with methyl green solution and mounted.

\section{Statistical analysis}

The significance of differences was analyzed statistically using Fisher's exact test, the compared $t$-test with Welch's correction, or the Mann-Whitney $U$ test, using SPSS software (Ver.18, SPSS Inc., Chicago, IL). In all cases, the level of significance was set at $P<0.05$.

\section{Results}

\section{Clinical features of the patients}

The mean ages at diagnosis of the patients with $\mathrm{AIH}$ and $\mathrm{PBC}$ were $58.3 \pm 15.2$ and $55.8 \pm 12.6$ years, respectively. The mean alanine aminotransferase (ALT) level in the patients with AIH was $369.7 \pm 406.0$ IU/l, which was significantly higher than in the patients with PBC $(81.5 \pm 103.3 \mathrm{IU} / 1, P<0.001)$ and the healthy donors $(15.7 \pm 5.2 \mathrm{IU} / 1, P<0.001)$. The mean IgG level in the patients with $\mathrm{AIH}$ was $2719.7 \pm 1322.2$ $\mathrm{mg} / \mathrm{dl}$, which was significantly higher than in the patients with PBC (1822.7 $\pm 725.6 \mathrm{mg} / \mathrm{dl}, P=0.001)$. ANA was positive in 29 of the patients with $\mathrm{AIH}$ $(82.8 \%)$ and in 24 of the patients with PBC $(80.0 \%)$. Information regarding the patient profiles and biochemical features is summarized in Table 1.

Table I. Patient characteristics.

\begin{tabular}{llll}
\hline & AIH & PBC & Control \\
\hline $\mathrm{n}$ & 35 & 30 & 30 \\
Age (years) & $58.3 \pm 15.2$ & $55.8 \pm 12.6$ & $57.5 \pm 19.2$ \\
& $(24-84)$ & $(30-73)$ & $(26-84)$ \\
Alb (g/dl) & $3.5 \pm 0.7$ & $4.2 \pm 0.5^{*}$ & $4.4 \pm 0.3^{*}, \dagger$ \\
& $(2.1-4.8)$ & $(2.6-4.8)$ & $(3.7-5.0)$ \\
IgG (mg/dl) & $2719.7 \pm 1322.2$ & $1822.7 \pm 725.6^{*}$ & ND \\
& $(794-6578)$ & $(837-3806)$ & \\
AST (IU/l) & $335.9 \pm 377.5$ & $76.7 \pm 84.3^{*}$ & $20.9 \pm 6.4^{*, * *}$ \\
& $(36-1728)$ & $(25-427)$ & $(15-44)$ \\
ALT (IU/1) & $369.7 \pm 406.0$ & $81.5 \pm 103.3^{*}$ & $15.7 \pm 5.2^{*, * *}$ \\
& $(39-1852)$ & $(18-530)$ & $(10-27)$ \\
ALP (IU/1) & $464.8 \pm 201.9$ & $606.4 \pm 419.1$ & $210.4 \pm 71.1^{*, * *}$ \\
& $(203-1301)$ & $(181-1755)$ & $(109-392)$ \\
T.Bil (mg/dl) & $6.7 \pm 7.9$ & $0.9 \pm 0.4^{*}$ & $0.7 \pm 0.2^{*, \dagger}$ \\
& $(0.8-27.3)$ & $(0.4-2.4)$ & $(0.3-1.1)$ \\
Plt.(x104/mm3) & $17.1 \pm 7.5$ & $19.5 \pm 6.1$ & $22.5 \pm 5.2^{*}$ \\
PT (\%) & $(3.8-32.7)$ & $(6.0-28.0)$ & $(11.9-32.8)$ \\
& $74.7 \pm 28.0$ & $97.4 \pm 12.8^{*}$ & ND \\
PT INR & $(20-121)$ & $(67-114)$ & \\
& $1.33 \pm 0.51$ & $1.01 \pm 0.07^{*}$ & ND \\
ANA positivity & $82.8 \%(29 / 35$ cases) & $80.0 \%(24 / 30$ cases) & ND \\
\hline Abbreviations: AIH, autoimmune hepatitis; PBC, primary biliary cirrhosis; Alb, \\
albumin; AST, aspartate aminotransferase; ALT, alanine aminotransferase; ALP, \\
alkaline phosphatase; T.Bil, total bilirubin; Plt, platelet count; PT, prothrombin \\
time; INR, international normalized ratio; ND, not determined.
\end{tabular}

\section{Presence of anti-HLA class II antibodies}

Anti-HLA class II antibodies were detected significantly more frequently in the patients with $\mathrm{AIH}$ $(88.1 \%)$ than in the patients with PBC $(33.3 \%, P$ $<0.001)$ or in the healthy donors $(13.3 \%, P<0.001)$ (Figure 1). Among the patients with $\mathrm{AIH}$, positive reactivity with the anti-HLA class II antibody was associated with higher serum transaminase levels (Figure 2).

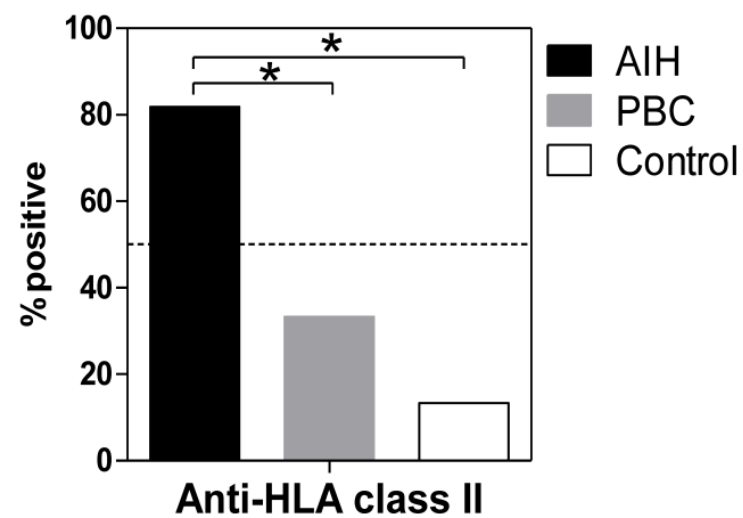

Figure I. Positivity for anti-HLA antibodies in sere from patients with AIH and PBC and from healthy controls. The presence of circulating antibodies against HLA class II molecules in sera was determined using fluorescent dye-impregnated beads bound to HLA molecules. The results from anti-HLA screening tests using multiplex technology are shown. ${ }^{*} P<0.01$ (compared with AlH).

\section{Presence of antibodies against self HLA class II alleles}

Table 2 shows the results of DNA typing of HLA class II alleles and the allele specificities of anti-HLA class II antibodies in each patient. We found that the anti-HLA class II antibodies detected in the patients with AIH showed specificity for several HLA class II alleles, especially DRB1 alleles (Table 2, right column). Moreover, after the determination of HLA class II alleles by DNA typing in each patient, we confirmed that anti-HLA class II antibodies with specificity for self HLA class II alleles were detected in four patients with AIH (Table 2, dashed alleles). Although the number of patients whose HLA class II alleles were determined by DNA typing was small, the ALT level was significantly higher in the patients with anti-self HLA class II antibodies than in the patients without anti-self HLA class II antibodies $(P=0.031)$ or without anti-HLA class II antibodies $(P=0.048)$ (Table 3$)$.

We then investigated the expression of HLA class II molecules in the liver using immunohistochemistry. Figure 3 shows representative results from a patient with $\mathrm{AIH}$ and a patient with PBC. In the livers of the patients with $\mathrm{PBC}$, in addition to mononuclear cells, including macrophages and B cells, HLA class II molecules were detected around the in- 
jured bile ducts, consistent with previous studies [19] (arrow in Figure 3). In contrast, HLA class II mole- cules were detected around hepatocytes in the livers of the patients with AIH (arrowhead in Figure 3).

Table 2. Comparison between HLA class II alleles defined by DNA typing and the allele specificities of anti-HLA class II antibodies in patients with AlH.

\begin{tabular}{|c|c|c|c|c|c|c|c|c|}
\hline \multirow[t]{2}{*}{ Age } & \multirow[t]{2}{*}{ Gender } & \multicolumn{6}{|c|}{ DNA typing } & \multirow{2}{*}{$\begin{array}{l}\text { Ab (Luminex) } \\
\text { Allele Specificity }\end{array}$} \\
\hline & & DRB1 & & DQB1 & & DPB1 & & \\
\hline 31 & $\mathrm{~F}$ & 04:03 & 15:01 & 03:03:02 & 06:02:01 & & & $D R B 1^{*} 04: 03$ \\
\hline 54 & $\mathrm{~F}$ & 04:05 & 08:03:02 & 03:02:01 & 06:01:01 & 02:02 & 05:01 & $\begin{array}{l}\text { DRB1*09:01, DRB1*04:03, DPB1*02:02, } \\
\text { DRB1*04:05 }\end{array}$ \\
\hline 66 & $\mathrm{~F}$ & 08:03:02 & 15:02:01 & 06:01:01 & & 02:01:02 & 05:01 & $\begin{array}{l}\text { DRB1*01:01, DRB1*04:03, DRB1*15:02, } \\
\text { DPB1*02:01 }\end{array}$ \\
\hline 82 & $\mathrm{~F}$ & 04:05 & 08:03 & 04:01 & 06:01 & 02:01 & 04:02 & $\begin{array}{l}\text { DRB1*04:03, DPB1*02:01, DPB1*04:02, } \\
\text { DRB1*04:05 }\end{array}$ \\
\hline 53 & $\mathrm{~F}$ & 04:05 & 08:02 & 04:01:01 & 04:02 & 05:01 & & DRB1*10:01, DQB1*06:01, DPB1*03:01 \\
\hline 59 & $\mathrm{~F}$ & 04:05 & 08:02 & 04:01:01 & 04:02 & 04:02 & 05:01 & DRB1*01:03, DRB1*01:01, DRB1*10:01 \\
\hline 67 & $\mathrm{~F}$ & 12:02:01 & $12: 10$ & 03:01:01 & & 05:01 & & DRB1*09:02 \\
\hline 67 & $\mathrm{~F}$ & 04:05 & 08:03 & 04:01 & 06:01 & 02:01 & 09:01 & DRB1*04:03 \\
\hline 72 & $\mathrm{~F}$ & 04:06 & 12:02:01 & 03:01:01 & 03:02:01 & & & DPB1*01:01, DPB1*20:01 \\
\hline
\end{tabular}

Abbreviations: HLA, human leukocyte antigen; AIH, autoimmune hepatitis; $\mathrm{Ab}$, antibodies; F, female.

Table 3. Comparison of patient characteristics based on the positivity of anti-HLA class II antibodies.

\begin{tabular}{|c|c|c|c|}
\hline & Anti-self HLA class II antibodies (+) & Anti-self HLA class II antibodies (-) & Anti-HLA antibodies (-) \\
\hline $\mathrm{n}$ & 4 & 5 & 8 \\
\hline Age (years) & $\begin{array}{l}58.3 \pm 21.5 \\
(31-82)\end{array}$ & $\begin{array}{l}63.6 \pm 7.5 \\
(53-72)\end{array}$ & $\begin{array}{l}52.4 \pm 17.3 \\
(24-72)\end{array}$ \\
\hline $\mathrm{Alb}(\mathrm{g} / \mathrm{dl})$ & $\begin{array}{l}3.2 \pm 0.9 \\
(2.4-4.2)\end{array}$ & $\begin{array}{l}3.5 \pm 0.9 \\
(2.1-4.6)\end{array}$ & $\begin{array}{l}3.7 \pm 0.4 \\
(2.8-4.1)\end{array}$ \\
\hline $\operatorname{IgG}(\mathrm{mg} / \mathrm{dl})$ & $\begin{array}{l}2271.8 \pm 787.2 \\
(1571-3381)\end{array}$ & $\begin{array}{l}2381.4 \pm 584.3 \\
(1873-3343)\end{array}$ & $\begin{array}{l}2809.4 \pm 2078.9 \\
(794-6578)\end{array}$ \\
\hline AST (IU/1) & $\begin{array}{l}829.5 \pm 635.2^{*, * *} \\
(231-1728)\end{array}$ & $\begin{array}{l}215.8 \pm 218.7 \\
(36-587)\end{array}$ & $\begin{array}{l}157.3 \pm 84.0 \\
(37-272)\end{array}$ \\
\hline $\operatorname{ALT}(\mathrm{IU} / \mathrm{l})$ & $\begin{array}{l}1054.8 \pm 671.8^{*, * *} \\
(208-1852)\end{array}$ & $\begin{array}{l}271.4 \pm 408.5 \\
(46-998)\end{array}$ & $\begin{array}{l}211.3 \pm 149.5 \\
(50-439)\end{array}$ \\
\hline T.Bil (mg/dl) & $\begin{array}{l}11.1 \pm 6.3 \\
(3.8-18.8)\end{array}$ & $\begin{array}{l}4.3 \pm 6.7 \\
(0.8-16.3)\end{array}$ & $\begin{array}{l}6.1 \pm 7.9 \\
(0.5-21.5)\end{array}$ \\
\hline Plt.(x104/mm³) & $\begin{array}{l}16.3 \pm 8.6 \\
(8.2-26.1)\end{array}$ & $\begin{array}{l}20.5 \pm 6.7 \\
(12.3-30.9)\end{array}$ & $\begin{array}{l}20.6 \pm 8.9 \\
(6.2-31.5)\end{array}$ \\
\hline PT INR & $\begin{array}{l}1.65 \pm 0.75 \\
(1.00-2.72)\end{array}$ & $\begin{array}{l}1.13 \pm 0.19 \\
(0.99-1.41)\end{array}$ & $\begin{array}{l}1.39 \pm 0.55 \\
(0.95-2.40)\end{array}$ \\
\hline ANA positivity & $75.0 \%$ (3/4cases) & $80.0 \%$ (4/5cases) & $100 \%$ (8/8cases) \\
\hline
\end{tabular}

${ }^{*} P<0.05$ (compared to HLA negative), ${ }^{* *} P<0.05$ (compared to self-HLA negative). Abbreviations: HLA, human leukocyte antigen; AIH, autoimmune hepatitis; PBC, primary biliary cirrhosis; Alb, albumin; AST, aspartate aminotransferase; ALT, alanine aminotransferase; ALP, alkaline phosphatase; T.Bil, total bilirubin; Plt, platelet count; PT, prothrombin time; INR, international normalized ratio.

A

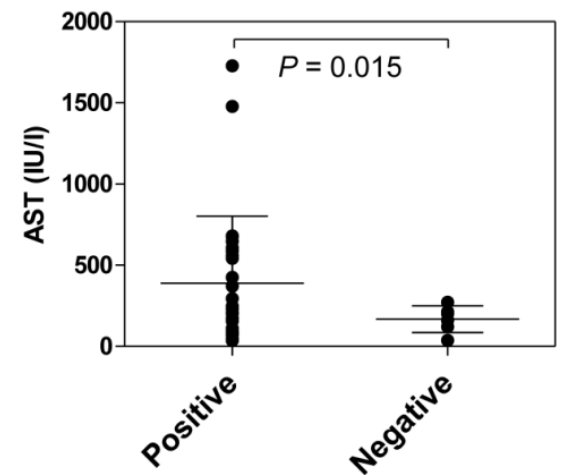

B

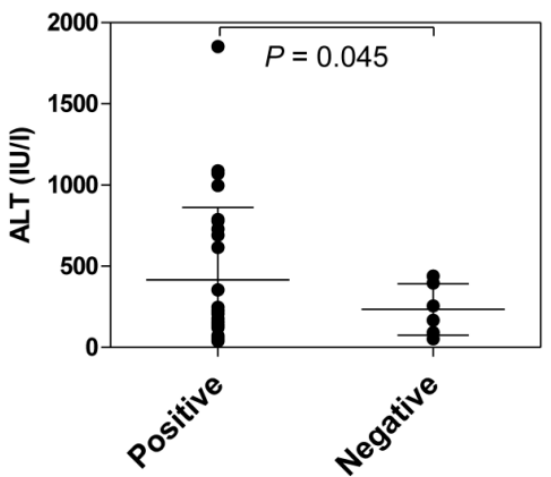

Figure 2. Comparison of serum transaminase levels between anti-HLA class II antibody-positive and -negative AlH patients at the onset of disease. The presence of anti-HLA class II antibodies in the sera was determined using fluorescent dye-impregnated beads bound to HLA molecules. Among the patients with AlH, positive reactivity with anti-HLA class II antibodies was associated with higher serum transaminase levels. 


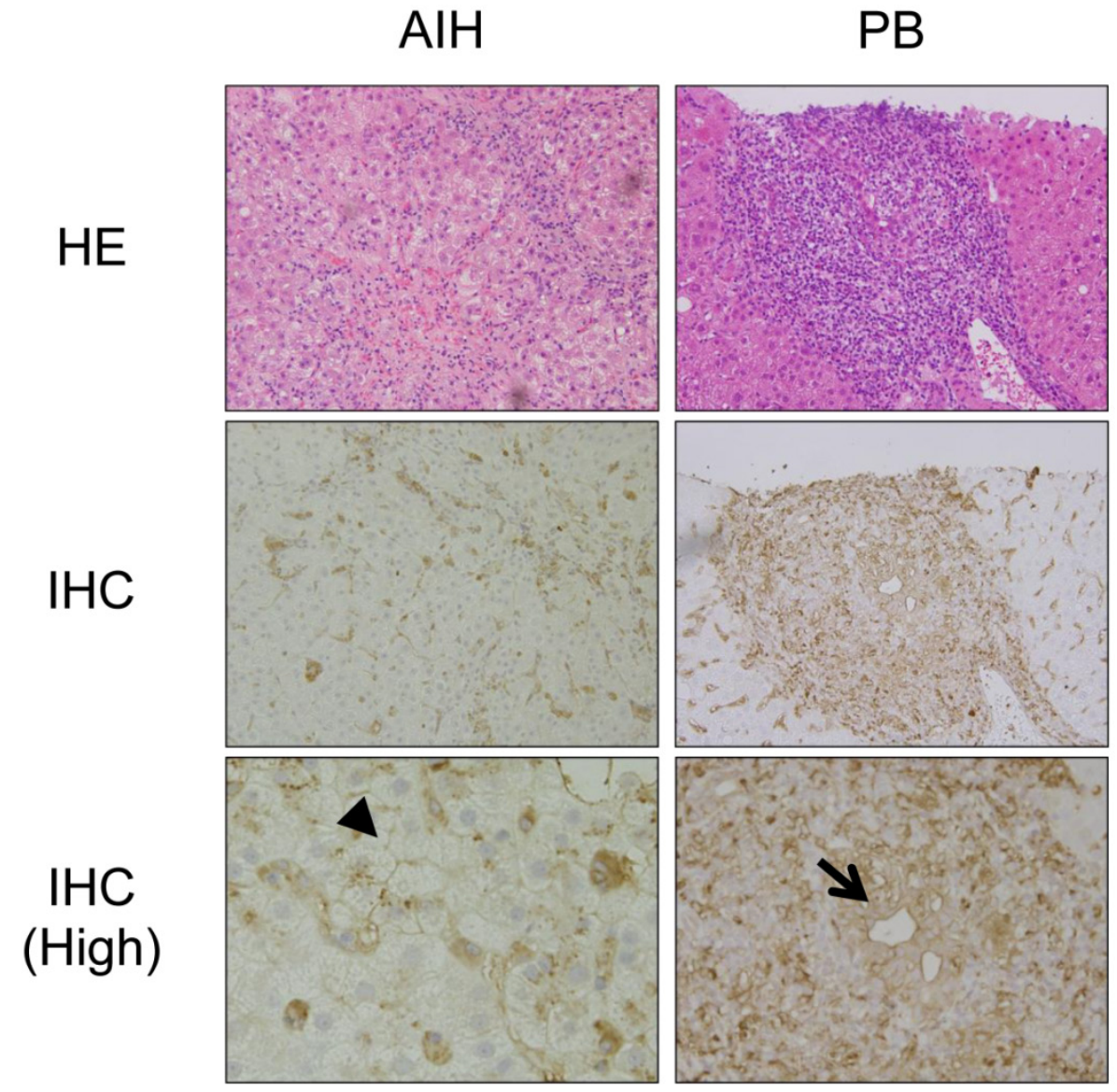

Figure 3. Immunohistochemical staining of HLA class II molecules in the livers of patients with PBC and AlH. Representative results from immunohistochemical staining (IHC) of HLA class II molecules in the livers of the patients with PBC and AlH are shown. HE staining results are also shown. (High) Higher magnification. In addition to mononuclear cells, including macrophages and B cells, HLA class II molecules are expressed around injured biliary epithelial cells (arrow) in the liver of a patient with PBC and around injured hepatocytes (arrowhead) in the liver of a patient with AlH.

\section{Discussion}

In the present study, we found that anti-HLA class II antibodies were detected significantly more frequently in patients with $\mathrm{AIH}$ than in patients with PBC or healthy donors. The positive reactivity with anti-HLA class II antibodies was associated with significantly higher serum transaminase levels in the patients with $\mathrm{AIH}$. We found that the anti-HLA class II antibodies detected in the patients with AIH showed specificity for several HLA class II alleles. Moreover, we confirmed that anti-HLA class II antibodies with specificity for self HLA class II alleles were detected in a proportion of the patients with AIH. Although HLA class II molecules are expressed on a restricted range of cells, such as antigen-presenting cells, they are also IFN- $\gamma$-inducible on other cells, including hepatocytes [13]. We also found that HLA class II molecules were expressed on hepatocytes in the livers of the patients with $\mathrm{AIH}$, consistent with previous reports $[20,21]$. These results suggest that an antibody-mediated immune response against HLA class II molecules on hepatocytes may be involved in the pathogenesis or acceleration of liver injury in $\mathrm{AIH}$.

Multiple genetic associations with $\mathrm{AIH}$ have been described in different ethnic groups [1]. The strongest genetic association in $\mathrm{AIH}$ is with genes that encode HLA class II molecules, especially DRB1 alleles [2,22-25]. The alleles that confer susceptibility to AIH-1 are HLA DRB1*03:01 and DRB1*04:01 in European and North American populations, as well as DRB1*04:05 and DRB1*04:04 in Japanese [26], Argentinean, and Mexican populations [24]. It has been speculated that different pathogens or environmental triggers generate diverse epitopes, which are each presented by different disease-associated HLA-DR molecules, inducing the clonal expansion of auto-reactive $\mathrm{T}$ cells and ultimately progressing to the same or a very similar form of the clinical disease $[24,27]$. However, the precise mechanism of the involvement of HLA-DR molecules in the susceptibility and pathogenesis of $\mathrm{AIH}$ remains to be elucidated. Interestingly, in the present study, we found that the anti-HLA class II antibodies detected in the patients with AIH showed specificity mainly to DRB1 alleles 
(Table 2). Although the reason why the anti-HLA class II antibodies detected in the patients with $\mathrm{AIH}$ showed such biased specificity to DRB1 alleles remains unknown, this may be associated with susceptibility to $\mathrm{AIH}$.

The ability to express major histocompatibility complex (MHC) class II molecules is normally restricted to professional antigen-presenting cells [28]. However, MHC class II molecules have been found on hepatocytes from patients with $\mathrm{AIH}$ and primary sclerosing cholangitis, although MHC class I molecules were invariably expressed on hepatocytes [21]. IFN- $\gamma$, which is primarily secreted by activated T cells and natural killer cells, is considered the main inducer of the expression of HLA class II molecules on hepatocytes $[13,29]$. It has been speculated that such aberrant expression of MHC class II molecules and antigen presentation by parenchymal cells may be the cause of autoimmune diseases [28]. Herkel et al. showed that MHC class II-expressing hepatocytes could present antigens and activate CD4 T cells, although the ability of hepatocytes to present antigens on MHC class II molecules did not appear to be sufficient to cause inflammatory autoimmunity or hepatitis [30]. In the present study, we found that HLA class II molecules were expressed on hepatocytes in the livers of the patients with $\mathrm{AIH}$, consistent with previous reports [20,21]. Moreover, we confirmed that anti-HLA class II antibodies with specificity for self HLA class II alleles were detected in patients with AIH. Involvement of an antibody-dependent cell mediated cytotoxicity (ADCC) in the pathogenesis of autoimmune liver damage has been suggested by the findings that hepatocytes, isolated from patients with $\mathrm{AIH}$, are coated with immunoglobulins and are susceptible to cytotoxicity when autologous Fc-receptor-bearing mononuclear cells $[29,31]$. Tu et al. showed that complement could play a pivotal role in liver-specific autoantibody-mediated hepatocyte injury in a murine model of AIH [32]. Therefore, our results have led to the hypothesis that such anti-self HLA class II antibodies could be directly involved in the pathogenesis of autoimmune liver damage in AIH. Considering that hepatocytes are the main immune target in $\mathrm{AIH}$, we believe that more attention should be paid to the expression of HLA class II molecules on hepatocytes.

The effects of preoperatively produced anti-HLA antibodies on organ transplantation outcomes have been demonstrated for kidney, heart, and lung transplantation [33]. Although the existence of such effects in LT is controversial, several reports have demonstrated the significance of donor-specific anti-HLA antibodies in rejection and outcome after LT using the Luminex assay and the histological examination of deposition of C4d, a marker of immunoglobulin-dependent activation of complement $[33,34]$. Previous studies have shown that a substantial proportion of clinical liver biopsies with specific signs of acute cellular and chronic rejection exhibit C4d deposition, strongly suggesting a role for a humoral component in liver allograft failure [35]. Moreover, Castillo-Rama et al. reported that increased rejection episodes were predominantly observed in allografts positive for Luminex-detected anti-HLA class II antibodies [34]. Although we did not find C4d deposition in the livers of the patients with $\mathrm{AIH}$ (data not shown), the above findings associated with allograft rejection suggest a possible involvement of antibody-mediated immune responses against HLA class II molecules on hepatocytes, including ADCC, in the pathogenesis of AIH.

In conclusion, we have demonstrated for the first time that anti-HLA class II antibodies were detected significantly more frequently in patients with $\mathrm{AIH}$ than in patients with PBC or healthy donors. We found that the anti-HLA class II antibodies detected in the patients with AIH showed specificity for several HLA class II alleles, mainly for DRB1 alleles. Moreover, we confirmed that anti-HLA class II antibodies with specificity for self HLA class II alleles were detected in a proportion of the patients with AIH. Although the present study should be confirmed by studies with larger numbers of patients, our results suggest the possible involvement of an antibody-mediated immune response against HLA class II molecules on hepatocytes in the pathogenesis or acceleration of $\mathrm{AIH}$.

\section{Abbreviations}

HLA, human leukocyte antigen; MHC, major histocompatibility; AIH, autoimmune hepatitis; PBC, primary biliary cirrhosis; MFI, mean fluorescence intensity; LT, liver transplantation.

\section{Acknowledgements}

The authors thank Dr. Kiyoe Masuo and Dr. Miwa Takasu (VERITAS Corporation, Tokyo, Japan) for excellent technical assistance.

\section{Funding}

This work was supported in part by Grants-in-Aid for Scientific Research (C) (24590963 to S.Y.) from Japan Society for the Promotion of Science (JSPS), and Grants-in Aid from the Ministry of Health, Labour, and Welfare of Japan to the Study Group of Intractable Hepatobiliary Diseases. 


\section{Competing Interest}

The authors have declared that no competing interest exists.

\section{References}

1. Manns MP, Czaja AJ, Gorham JD, et al. Practical guidelines of the American Association for the Study of Liver Diseases. Diagnosis and management of autoimmune hepatitis. Hepatology. 2010; 51: 2193-213.

2. Czaja AJ, Manns MP. Advances in the diagnosis, pathogenesis, and management of autoimmune hepatitis. Gastroenterology. 2010; 139: 58-72.e4

3. Vergani D, Alvarez F, Bianchi FB, et al. Liver autoimmune serology: a consensus statement from the committee for autoimmune serology of the International Autoimmune Hepatitis Group. J Hepatol. 2004; 41: 677-83.

4. Muratoi L, Parola M, Ripalti A, et al. Liver/kidney microcomal antibody type 1 targets CYP2D6 on hepatocyte plasma membrane. Gut. 2000; 46: 553-61.

5. Gossard AA, Lindor KD. Autoimmune hepatitis: a review. J Gastroenterol. 2012; 47: 498-503.

6. Liberal R, Longhi MS, Grant CR, Mieli-Vergani G, Vergani D. Autoimmune hepatitis after liver transplantation. Clin Gastroenterol Hepatol. 2012; 10: 346-53.

7. Neuberger J, Portmann B, Calne R, et al. Recurrence of autoimmune chronic active hepatitis following orthotopic liver grafting. Transplantation. 1984; 37: 363-5.

8. Kerkar N, Hadzic N, Davies ET, et al. De novo autoimmune hepatitis after liver transplantation. Lancet. 1998; 351: 409-13.

9. Vergani D, and Mieli-Vergani G. The impact of autoimmunity on hepatocytes. Semin Liver Dis. 2007; 27: 140-51.

10. Neil DAH, Hubscher SG. Current views on rejection pathology in liver transplantation. Transpl Int. 2010; 23: 971-83.

11. O'Leary JG, Kaneku H, Susskind BM, Jennings LW, Neri MA, Davis GL, et al. High mean fluorescence intensity donor-specific anti-HLA antibodies associated with chronic rejection postliver transplant. Am J Transplant. 2011; 11: 1868-76.

12. Miyagawa-Hayashino A, Yoshizawa A, Uchida Y, Egawa H, Yurugi K, Masuda $\mathrm{S}$, et al. Progressive graft fibrosis and donor-specific human leukocyte antigen antibodies in pediatric late liver allografts. Liver Transpl. 2012; 18: 1333-42.

13. Horras CJ, Lamb CL, Mitchell KA. Regulation of hepatocyte fate by interferon-y. Cytokine Growth Factor Rev. 2011; 22: 35-43.

14. Alvarez F, Berg PA, Bianchi FB et al. International Autoimmune Hepatitis Group Report: review of criteria for diagnosis of autoimmune hepatitis. J Hepatol. 1999; 31: 929-38.

15. Hennes EM, Zeniya M, Czaja AJ et al. Simplified criteria for the diagnosis of autoimmune hepatitis. Hepatology. 2008; 48: 169-76.

16. Kaplan MM, Gershwin ME. Primary biliary cirrhosis. N Egl J Med. 2005; 353: 1261-73

17. Selmi C, Bowlus CL, Gershwin ME, Coppel RL. Primary biliary cirrhosis. Lancet. 2011; 377: 1600-9.

18. Tait BD, Hudson F, Cantwell L, Brewin G, Holdsworth R, Bennet G, Jose M. Review article: Luminex technology for HLA antibody detection in organ transplantation. Nephrology. 2009; 14: 247-54.

19. Ballardini G, Mirakian R, Bianchi FB, Pisi E, Doniach D, Bottazzo GF. Aberrant expression of HLA-DR antigens on bileduct epithelium in primary biliary cirrhosis: relevance to pathogenesis. Lancet. 1984; 2: 1009-13.

20. Franco A, Barnaba V, Natali P, Balsano C, Musca A, Balsano F. Expression of class I and class II major histocompatibility complex antigens on human hepatocytes. Hepatology. 1988; 8: 449-54.

21. Senaldi G, Lobo-Yeo A, Mowat AP, Mieli-Vergani G, Vergani D. Class I and class II major histocompatibility complex antigens on hepatocytes: importance of the method of detection and expression in histologically normal and diseased livers. J Clin Pathol. 1991; 44: 107-14.

22. Doherty DG, Donaldson PT, Underhill JA, Farrant JM, Duthie A, Mieli-Vergani G, et al. Allelic sequence variation in the HLA class II genes and proteins in patients with autoimmune hepatitis. Hepatology. 1994, 19: 609-15.

23. Seki T, Ota M, Furuta S, Fukushima H, Kondo T, Hino K, et al. HLA class II molecules and autoimmune hepatitis susceptibility in Japanese patients. Gastroenterology. 1992; 103: 1041-7.

24. Mielil-Vergani G, Vergani D. Autiummune hepatitis. Nat Rev Gastroenterol Hepatol. 2011; 8: 320-9.

25. Oliveira LC, Porta G, Marin MLC, Bittencourt PL, Kalil J, Glidberg AC. Autoimmune hepatitis, HLA and extended haplotypes. Autoimmun Rev. 2011; 10: 189-93.

26. Yoshizawa K, Umemura T, Ota M. Genetic background of autoimmune hepatitis in Japan. J Gastroenterol. 2011; 46 Suppl 1: 42-7.

27. Lieberal R, Grant CR, Mieli-Vergani G, Vergani D. Autoimmune hepatitis: a comprehensive review. J Autoimmun. 2013; 41: 126-39.

28. Ting JP, Trowsdale J. Genetic control of MHC class II expression. Cell. 2002. 109(Supl): S21-S33.

29. Liberal R, Longhi MS, Mieli-Vergani G, Vergani D. Pathogenesis of autoimmune hepatitis. Best Prac Res Clin Gastroenterol. 2011; 25: 653-64.
30. Herkel J, Jagemann B, Wiegard C, Lazaro JFG, Lueth S, Kanzler S, et al. MHC class II-expressing hepatocytes function as antigen-presenting cells and activate specific CD4 T lymphocytes. Hepatology. 2003; 37: 1079-85.

31. Longhi MS, Ma Y, Mieli-Vergani G, Vergani D. Aetipathogenesis of autoimmune hepatitis. J Autoimmun. 2010; 34: 7-14.

32. Tu Z, Li Q, Chou HS, Hsieh CC, Meyerson H, Peters MG, et al. Complement mediated hepatocytes injury in a model of autoantibody induced hepatitis. Immunobiology. 2011; 216: 528-34.

33. Yoshizawa A, Egawa H, Yurugi K, Hishida R, Tsuji H, Ashihara E, et al. Significance of semiquantitative assessment of preformed donor-specific antibody using Luminex single bead assay in living related liver transplantation. Clin Dev Immunol. 2013; 20113: 972705.

34. Musat AI, Agni RM, Wai PY, Pirsch JD, Lorentzen DF, Powell A, et al. The significance of donor-specific HLA antibodies in rejection and ductopenia development in ABO compatible liver transplantation. Am J Transplant. 2011; 1: $500-10$.

35. Castillo-Rama M, Castro MJ, Bernardo I, Meneu-Diaz JC, Elola-Olaso AM, Calleja-Antolin SM, et al. Preformed antibodies detected by cytotoxic assay or multibead array decrease liver allograft survival: role of human leukocyte antigen compatibility. Liver Transpl. 2008; 14: 554-62. 